\title{
A Conceptual Framework for Sustainable Manufacturing by Focusing on Risks in Supply Chains
}

\author{
Masaru Nakano \\ The Graduate School of System Design and Management, Keio University, \\ Kyosei Building, 4-1-1, Hiyoshi, Kohoku-ku, Yokohama, Kanagawa, 223-8526, Japan \\ m.nakano@sdm.keio.ac.jp
}

\begin{abstract}
Sustainable manufacturing is becoming a popular concept. However, the definition is not clear, and technical approaches are not specified in conventional studies.

This study proposes a conceptual framework for understanding sustainable manufacturing from the viewpoint of risks in manufacturing enterprises and supply chains. Two aspects of sustainable manufacturing are defined: manufacturing for a sustainable society and sustainability of the manufacturing sector.

A technical approach is relevant to visualization techniques in systems engineering. The study categorizes risk and sustainability factors of manufacturing enterprises into four sections: internal, supply chain, manufacturing, and global society. Inter-sectional analysis is important for resolving environmental issues. In addition, this study categorizes methods for risk management corresponding to different time scales and frequencies.
\end{abstract}

Keywords: Sustainable Manufacturing, Supply Chain, Risk Management.

\section{Introduction}

The concept of sustainable manufacturing is becoming an important issue in the context of concern about the environment. Many studies, such as Jovane et al. [1] and Westkämper et al. [2], described the background, needs, and major conceptual steps from economic growth to sustainable development. However, the definition of sustainable manufacturing is not clear. In this study, two aspects of sustainable manufacturing are defined: manufacturing for a sustainable society and sustainability of the manufacturing sector. The definition is consistent with a well-known definition of sustainability that combines economic, environmental, and social dimensions (for example, see Sutherland et al. [3] and Seuring and Muller [4]).

Studies on sustainable supply chains have increased recently regarding the risk of supply chain disruption and green supply chains [4]. A survey with case studies related to disruption and resilience in supply chains is provided by Sheffi [5] by considering a combination of risk and competence in enterprises. Nakano [6] discusses mid-term flexibility, adaptability, and changeability in designing manufacturing systems against market risk. A conceptual framework for inverse manufacturing (see Srivastava [7]) is provided with economic criteria of a focal company for a green 
supply chain. This paper not only considers an enterprise or a supply chain but also emphasizes collaboration of industrial sectors, and proposes a conceptual framework by focusing on risks in enterprises and supply chains in the two aspects of sustainable manufacturing. The idea goes from sustainable society to sustainable enterprise through sustainable manufacturing and sustainable supply chains. The conceptual relationship is illustrated in Figure 1.

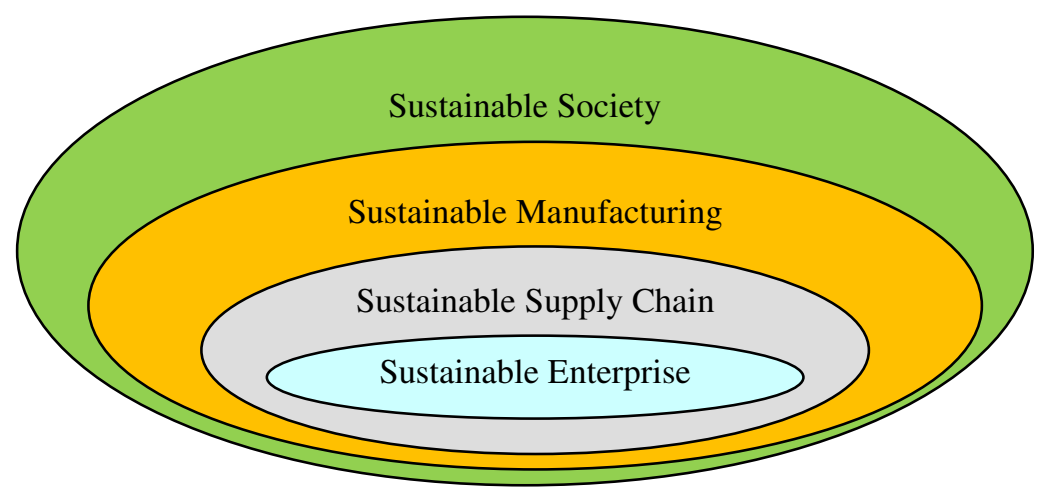

Fig. 1. Conceptual relationship between concepts relevant to sustainable manufacturing

Section two categorizes the risks of manufacturing enterprises from different perspectives. A sustainable supply chain is defined in this study as a value chain in manufacturing for the sustainability of society, industrial sectors, and manufacturing enterprises under constraints of social needs and supply networks. The study also categorizes methods for risk management corresponding to different cases in terms of timescale and frequency.

Section three proposes methods to visualize and analyze problems in sustainable manufacturing by using systems engineering techniques (see Haskins et al. [8] and Forsberg et al. [9]). Section four describes a method for inter-sectional analysis of sustainable manufacturing. The topic connects sustainable manufacturing and sustainable supply chains. Section five concludes the paper and describes future work.

\section{Risk and Sustainability of Manufacturing Enterprises}

Figure 2 illustrates four categories of risks and sustainability for manufacturing enterprises. The enterprise has dishonesty risks such as fraud and leaks, which may lead it to sudden death. Upstream or downstream risks exist in supply chains. They include disruptive risks from social catastrophes such as natural disasters, civil war, and financial crisis, and competitive risks in business such as M\&A and innovation by competitors. There may be dishonesty for intellectual property rights (IPR) in developing countries. In addition, we should also consider risks related to social factors such as global warming, shortage of energy and material resources, and an aging 
society. Most public sectors concern risks to the manufacturing sector in their regions. Another risk is change in the industrial structure. Green policies may change the structure dramatically and threaten specified sectors.

Consider Figures 1 and 2. Sustainable manufacturing consists of two issues: green manufacturing, which is manufacturing with a low burden on the natural environment, and sustainability of the manufacturing sector. Green manufacturing employs energyefficient, material-efficient, and pollution-free technologies in manufacturing. Similarly, a green supply chain, which places a small burden on the environment, employs techniques such as closed-loop supply chains and lifecycle engineering.

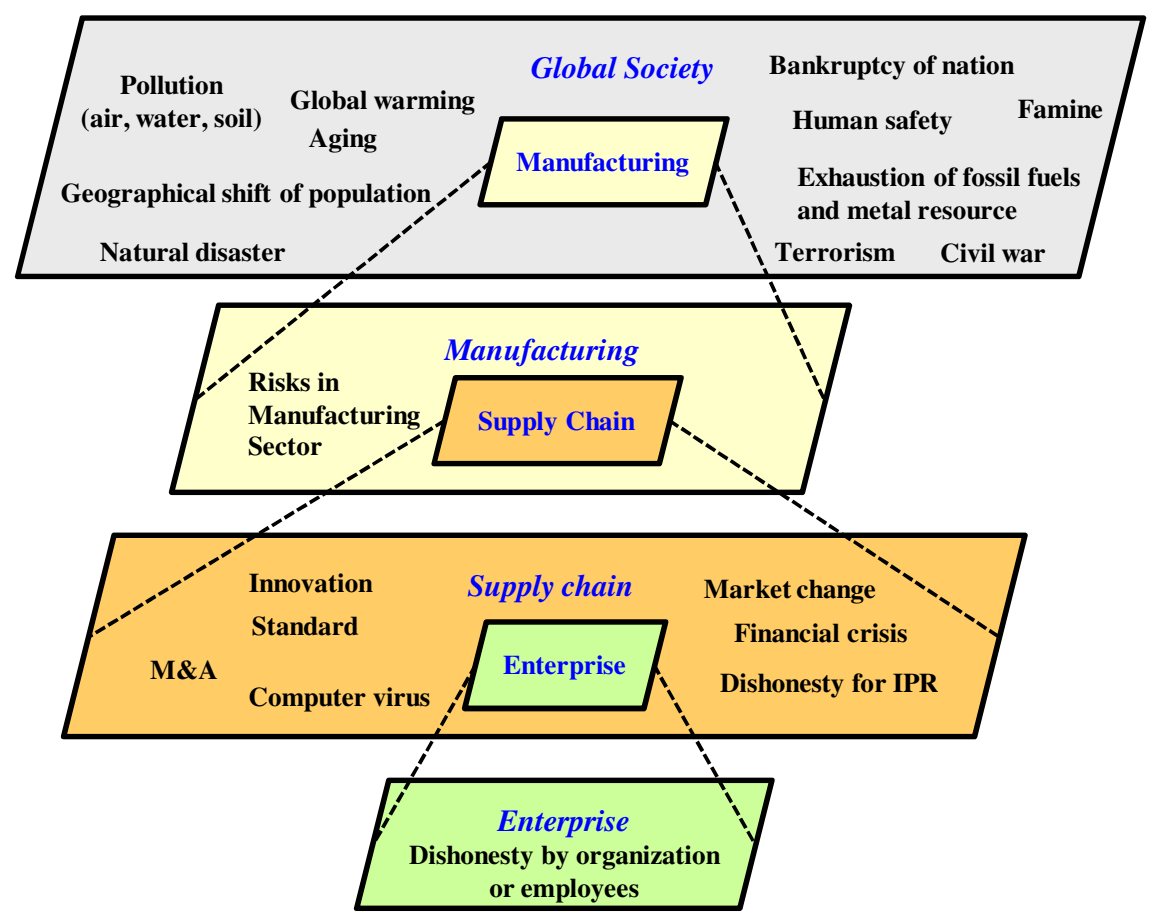

Fig. 2. Risks to enterprises

Risks in global society, such as global warming and material shortages, are longterm risks, which are supposed to predict future occurrences and their timing. Collaborative efforts to design and improve the social system should be made to mitigate these risks, because delayed actions may be too late for recovery. Risks for manufacturing sectors are also predictable if you look at the history of the automobile sector. On the other hand, the exact timing of disruptive and competitive risks, such as financial crises and natural disasters, cannot be predicted, and therefore monitoring capability and quick response are more important. We call this kind of risk unpredictable risks. As for risks arising inside enterprises, continuous management is essential. Table 1 summarizes risks and appropriate responses. Because 
Table 1. Main approaches to avoiding risks and fostering sustainability

\begin{tabular}{|l|l|c|c|c|}
\hline \multicolumn{2}{|c|}{ Main Approach } & Management & $\begin{array}{l}\text { Monitoring } \\
\text { and } \\
\text { Resilience }\end{array}$ & $\begin{array}{l}\text { Prediction } \\
\text { and System } \\
\text { Design }\end{array}$ \\
\hline \multicolumn{2}{|l|}{ Inside Enterprise } & $\bullet$ & $\boldsymbol{\Delta}$ & \\
\hline \multirow{3}{*}{$\begin{array}{l}\text { Supply } \\
\text { Network }\end{array}$} & Disruptive & & $\bullet$ & $\boldsymbol{\bullet}$ \\
\cline { 2 - 5 } & Competitive & & $\bullet$ & \\
\cline { 2 - 5 } & Green & & & $\bullet$ \\
\hline \multirow{2}{*}{ Manufacturing } & Green & & $\boldsymbol{\bullet}$ & $\bullet$ \\
\cline { 2 - 5 } & Sector & & & $\bullet$ \\
\hline Society & & & & \\
\hline
\end{tabular}

internal risks also occur in non-manufacturing enterprises, the following sections exclude internal risks.

\section{Systems Engineering for Sustainable Manufacturing}

This section considers a methodology to mitigate risks and foster sustainability of manufacturing enterprises. The underlying approaches come from systems engineering. A V-shaped model (Vee) is well known as a process model to design and manage systems, and includes the following steps: problem definition and requirement analysis, system design and decomposition, component design, development and implementation, integration, verification, and validation. A Vee model to evaluate technologies and policies in green manufacturing is proposed, as shown in Figure 3.

Global warming and material exhaustion are risks that we already understand, and it may be too late if we tackle them in the future. Therefore, as the first step, the stakeholders should estimate future risks, set a goal to prevent catastrophe, and collaboratively design a social system and a supply network. A technology road map should be made to develop a new system design for sustainable manufacturing. The dotted lines suggest that the left box is a starting point and the right box is the corresponding end point. The deliverable will be a proposal to the public in most cases.

A Vee model for monitoring and resilience in supply chains is proposed, as shown in Figure 4.

It is important to monitor occurrences of risks and use simulations to prepare for quick recovery because you cannot estimate the exact timing. The author proposes a 
multi-view modeling technique to visualize the problem's mechanism and design new supply chain architecture. The multi-view model consists of an event model, a risk model, and a management model, as shown in Figure 5.

The event model represents the relationship between causes and problems by investigating past cases, and provides scenarios for what can happen in the future. The dotted arrows represent risk mitigation factors while fault tree analysis FTA represents only paths that cause problems. The risk model evaluates risks mathematically by computing the probability of occurrences and multiplying by the cost of damage. The risks, occurrences, and damages are provided in probabilistic distribution. The arc represents probability of transition. The management model has the corresponding tasks and organization to monitor risk occurrences and respond quickly.

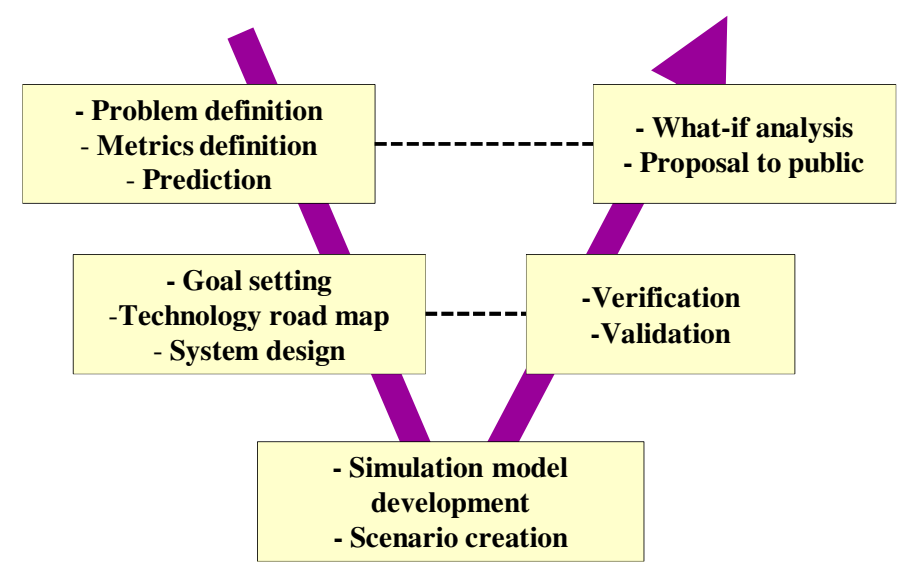

Fig. 3. A Vee model for system design in green manufacturing

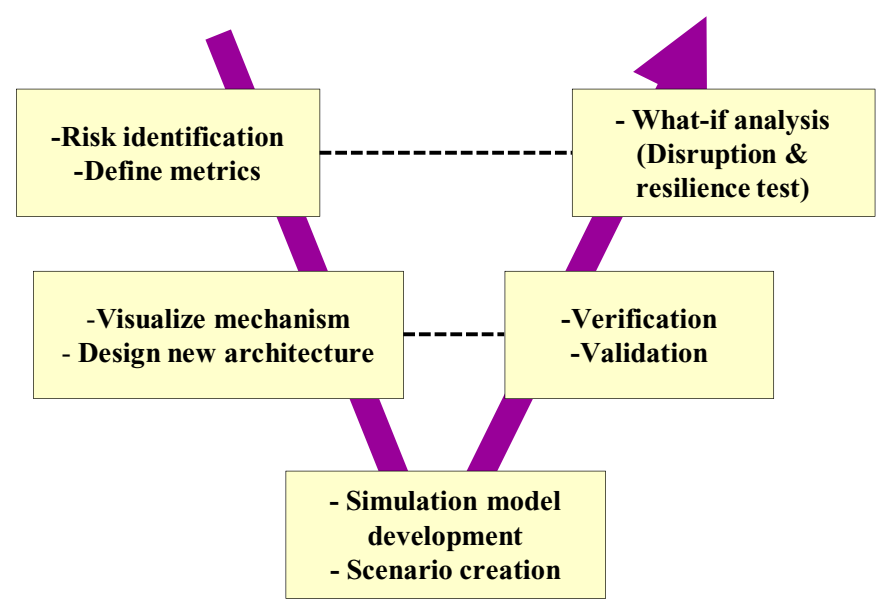

Fig. 4. A Vee model for monitoring and resilience in supply chains 


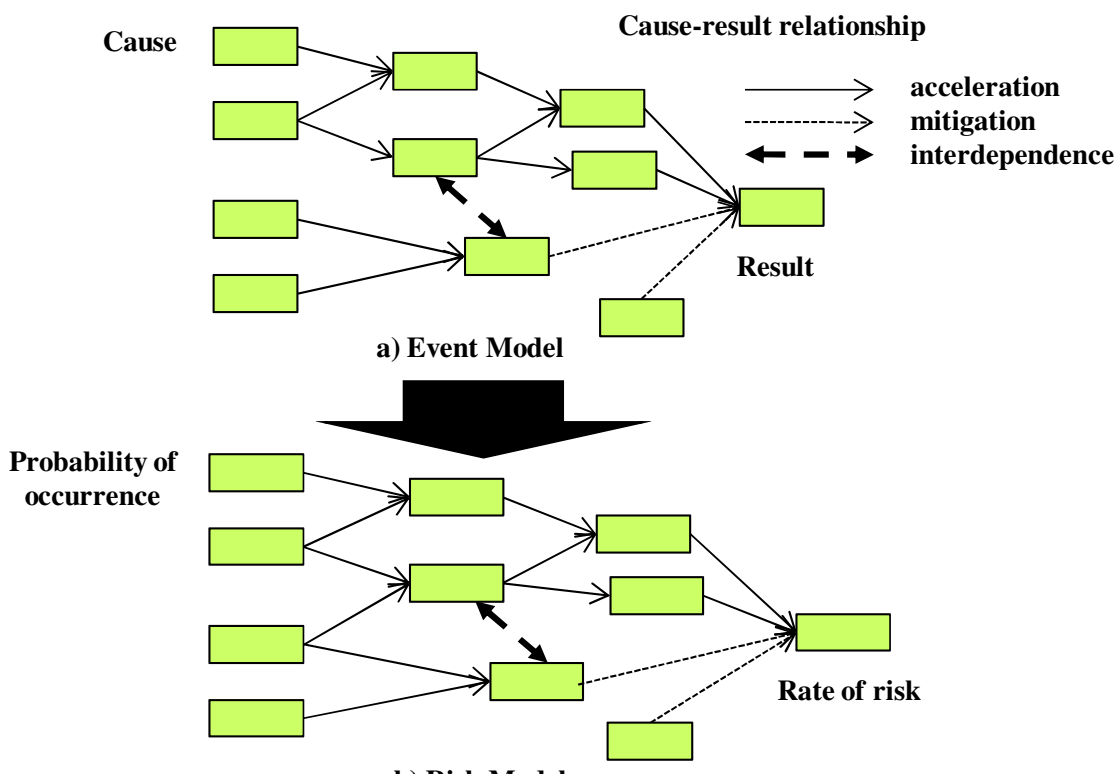

b) Risk Model

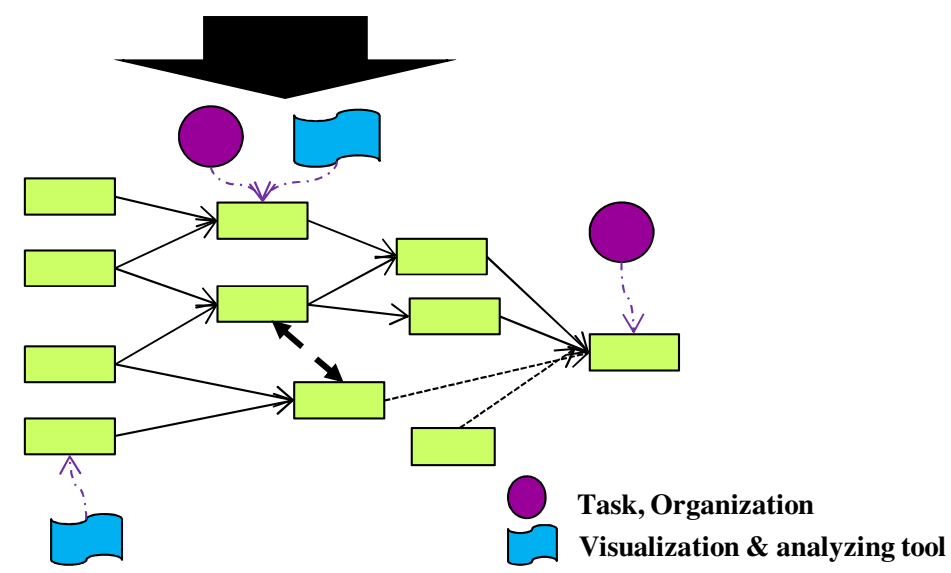

c) Management Model

Fig. 5. A multi-view model to mitigate risks in supply chains

\section{Inter-sectional Analysis of Green Sustainable Manufacturing and Green Supply Chains}

Figure 6 shows a concept for analyzing green sustainable manufacturing and green supply chains. Forecasting of macro-economic concerns, such as global warming, energy shortages, and material exhaustion, is necessary for goal-setting. The microstakeholders are consumers and enterprises. Enterprises have the role of designing environmentally friendly products in terms of product life cycle management (PLM) 
and life cycle engineering (LCE), while consumers regulate enterprise behaviors. However, the intermediate part is important to connect macro-level prediction regarding the global economy and environment with goals regarding time, space, and life cycle on which consumers and enterprises rely. The analysis includes life cycle assessment (LCA), calculation of carbon footprints, and design for recycling systems through industries related to product life cycles: mining, refining, material making, power/water supply, distribution, chemical, machining, processing, assembly, construction, transportation, and so on.

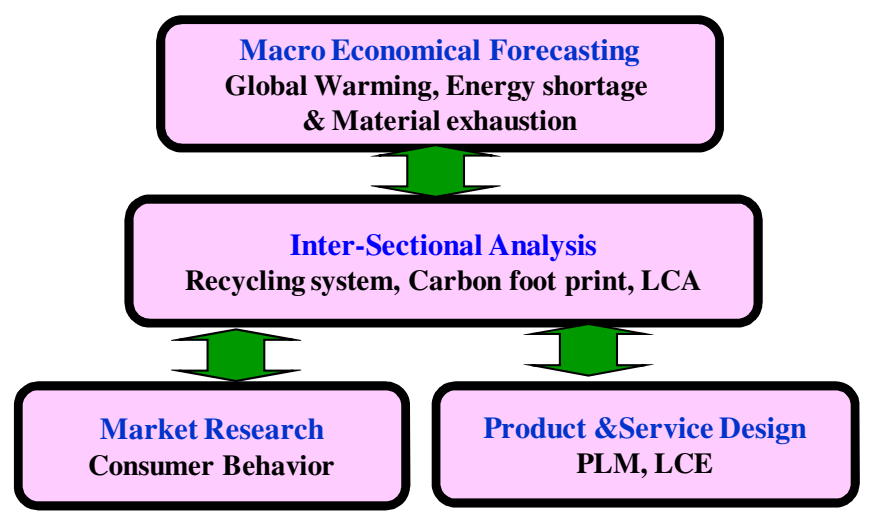

Fig. 6. System design for green sustainable manufacturing

A material selection problem in the automotive industry is discussed as a sample. Aluminum may be substituted for steel in car bodies more than is currently done. Aluminum is environmentally better than steel in driving due to its lighter weight, but worse to produce in terms of energy and water resource use. It is essential that all aluminum is recycled to the primary material. A dedicated study was done by NEDO [10] using life cycle assessment. Exhaustion of copper resources is threatened by increasing use in motors, and aluminum is expected to substitute for copper. However, more aluminum use may cause a material shortage. To visualize the triple relationship in the context of systems engineering, we need to deal with demand and supply in the future and collect data on items such as trading and accumulated volumes, which can be recycled in the future.

To encourage a recycling society, we may change our habit of product possession to that of rental or lease because the rental system is good for guaranteeing recycling. The industrial sector faces big risks because the change of our habit can cause a dramatic change in industrial structure in the future. We have three views, time-wise, spacewise, and life-cycle-wise: when a metal material approaches exhaustion and when other metals should be substituted, that is, time-wise; which countries should be affected by the crisis and what policy can be effective to mitigate the risk worldwide, that is, space-wise; and which sectors should collaborate in providing their data, that is, life-cycle-wise. To analyze this issue, data are needed to estimate accumulated stocks in used products, demand/production forecasting, and recycling technology from many sectors such as mining, automobiles, electrical appliances, and construction. 


\section{Conclusion}

The study discusses multiple views of sustainable manufacturing and proposes a conceptual framework to visualize and analyze relevant research topics. The discussion includes sustainable society, sustainable supply chains, and risks, as well as sustainable manufacturing. In addition, this study proposes three views, time-wise, spacewise, and life-cycle-wise, and three approaches, management, monitoring and resilience, and forecasting and system design.

The studies included in the paper remain conceptual in this field. Therefore, a future work will be a case study to verify and improve this concept.

Acknowledgments. This work was supported in part by a Grant in Aid from the Global Center of Excellence Program for "Center for Education and Research of Symbiotic, Safe and Secure System Design" from the Ministry of Education, Culture, Sport, and Technology in Japan.

\section{References}

1. Jovane, F., Yoshikawa, H., Alting, L., Boer, C.R., Westkamper, E., Williams, D., Tseng, M., Seliger, G., Paci, A.M.: The Incoming Global Technical and Industrial Revolution towards Competitive Sustainable Manufacturing. CIRP Annals - Manufacturing Technology 57, 641-659 (2008)

2. Westkämper, E., Alting, L., Arndt, G.: Life Cycle Management and Assessment: Approaches and Visions towards Sustainable Manufacturing. Proceedings of Institution of Mechanical Engineering, Part B 215, 599-626 (2001)

3. Sutherland, J.W., Rivera, J.L., Brown, K.L., Law, M., Hutchins, M.J., Haapala, K.R.: Challenges for the Manufacturing Enterprise to Achieve Sustainable Development. In: The 41st CIRP Conference on Manufacturing Systems, pp. 15-18 (2008)

4. Seuring, S., Muller, M.: From a Literature Review to a Conceptual Framework for Sustainable Supply Chain Management. Journal of Cleaner Production 16, 1699-1710 (2008)

5. Sheffi, Y.: The Resilient Enterprise: Overcoming Vulnerability for Competitive Advantage, pp. 1--352. MIT Press, Cambridge (2005)

6. Nakano, M., Noritake, S., Ohashi, T.: A Lifecycle Simulation Framework for Production Systems. In: Lean Business Systems and Beyond, pp. 327-335. Springer, Boston (2008)

7. Srivastava, S.K.: Network Design for Reverse Logistics. Omega-International Journal of Management Science 36, 535-548 (2008)

8. Haskins, C., Forsberg, K., Kruger, M. (eds.): System Engineering Handbook - A Guide for System Life Cycle processes and Activities, version 3.1, International Council on System Engineering, INCOSE (2007)

9. Forsberg, K., Mooz, H., Cotterman, H.: Visualizing Project Management: Models and Frameworks For Mastering Complex Systems, pp. 1-480. John Wiley \& Sons Inc., Chichester (2005)

10. NEDO committee report (Japanese), Life Cycle Assessment of Aluminum for Automotive Material (2005),

http://www.nedo.go.jp/iinkai/kenkyuu/bunkakai/17h/jigo/

10/1/4-1_9.pdf 